\title{
Ética médica e bioética
}

\section{Bioethics and medical ethics}

\author{
Reinaldo Ayer de Oliveira ${ }^{1}$
}

Oliveira RA de. Ética médica e bioética. Saúde, Ética \& Justiça. 2005;10(1/2):26-8.

RESUMO: A expressão ética médica pode ser definida como aquilo que os médicos tomaram por hábito denominar "o cumprimento ao determinado pelo código de ética: deveres e direitos dos médicos". A bioética afirma-se como uma área do conhecimento humano que relaciona os valores éticos com fatos biológicos sobretudo aqueles fatos que envolvem a vida e a saúde do seres humanos dentro de um meio ambiente adequado.

DESCRITORES: Ética médica. Bioética.

$\mathrm{O}$ $s$ valores e os costumes da profissão médica ocidental remontam ao século $\checkmark$ a. C. quando de lá nos foram trazidos os primeiros ensinamentos da arte e da prática da medicina que modelaram o exercício desta profissão por muitos anos de acordo com uma determinada visão ética. O Juramento de Hipócrates contém princípios éticos que nortearam o exercício profissional por muitos anos dando um sentido paternalista na relação do médico com o paciente. A palavra paciente que define uma pessoa enquanto na dependência de um médico ou aquela pessoa que recebe a ação de um agente expressa este significado ético/paternalista que ao longo da história regularam a atitude, o comportamento e, sobretudo, a ação dos médicos. A regulação da ação do médico está contida nos códigos. A expressão ética médica pode ser definida como aquilo que os médicos tomaram por hábito denominar "o cumprimento ao determinado pelo código de ética: deveres e direitos dos médicos". Os códigos têm um sentido eminentemente prático: tratase de analisar situações que exigiram decisões do médico e que poderão, ou não estarem "de acordo" com o código de ética do exercício profissional'.

O código de ética médica resulta de decisão da categoria fixando os limites morais de comportamento e atitudes do médico em diversas situações, estruturadas em capítulos. Por ser um documento doutrinário e prático o código reflete o pensamento e as posições da categoria num determinado momento, o de sua elaboração e aprovação².

\footnotetext{
${ }^{1}$ Professor Doutor do Departamento de Medicina Legal, Ética Médica e Medicina Social e do Trabalho da Faculdade de Medicina da Universidade de São Paulo. Conselheiro do Conselho Regional de Medicina do Estado de São Paulo.

Endereço para correspondência: Rua Teodoro Sampaio, 115 - CEP 05405-00 - São Paulo, SP. E-mail ayer@usp.br
} 
Permanece em vigência até que a própria categoria dos médicos decida mudá-lo por considerálo, por exemplo: obsoleto. O Conselho Federal de Medicina e os Conselhos Regionais tratam de fiscalizar o exercício profissional verificando por meio de dispositivos administrativos (Processo Ética Profissional) a infração ética ao Código ${ }^{3}$.

Atualmente, com o avanço científico e tecnológico na área médica além dos deveres e direitos contidos nos Códigos de Ética Médica dos Conselhos de Medicina, por meio de resoluções, procuram estabelecer diretrizes que orientam os médicos em situações de dificuldade ou de conflito na sua prática cotidiana. Isto pode ocorrer quando a prática médica, com a adoção dos avanços científicos, encontra dificuldade de interpretação dentro do prescrito pelo código. O médico tem se deparado com situações de conflito ético em várias áreas como nos casos de definições sobre a reprodução assistida, o início da vida, a doença terminal, a alocação de recursos e tantos outros. Portanto, pode surgir conflitos com relação à atitude que o médico deve assumir diante de situações que estão contidas no Código de Ética Médica. Estas situações tem sido debatidas não só no meio médicos como também tem envolvido a participação de outros profissionais da área de saúde e fora dela, inclusive nos meios de comunicação com expressiva participação de pessoas e grupos sociais.

Se entendermos que a ética médica trata dos médicos no universo da sociedade organizada em torno de dispositivos de legalidade e de ética do exercício da medicina; entendemos que a bioética surgiu da necessidade debater e decidir sobre as questões éticas relacionadas com os avanços científicos: "ela é a expressão crítica do nosso interesse em usar convenientemente os progressos da medicina e da ciência"4.

A bioética afirma-se como uma área do conhecimento humano que relaciona os valores éticos com fatos biológicos sobretudo aqueles fatos que envolvem a vida e a saúde do seres humanos dentro de um meio ambiente adequado. Quanto incorpora uma dimensão social a bioética torna-se por natureza pluralista, complexa e necessariamente, multidisciplinar ${ }^{5}$.

Neste aspecto, há diferença entre bioética e ética médica pois enquanto a primeira deve ser entendida como uma reflexão que se estrutura de modo multidisciplinar, em diálogo contínuo com as diversas áreas do conhecimento interessadas nos fenômenos da vida, da saúde e do meio ambiente, a ética médica tem como referencial o Código de Ética Médica como ponto de partida para a reflexão sobre os aspectos éticos envolvidos da ação do médico.
Não obstante é preciso entender que os conceitos de Bioética e de Ética Médica, se referem a duas esferas do saber e do comportamento humanos que mesmo em campos diversos, eles convergem quando são consideradas as relações entre a ciência e a ética ou como preferem alguns estudiosos para a expressão: a ética da ciência.

No campo das ciências da saúde a ética se refere, sobretudo, aos problemas envolvidos com os pesquisadores que se deparam em suas atividades com questões éticas na procura do conhecimento universal e objetivo, organizado sob a forma de teorias. Assim, as experiências que objetivam um conhecimento novo devem ser planejadas com cuidado e rigor científicos; e especialmente, quando se trata de um experimento envolvendo seres humanos 0 planejamento não deve expor o sujeito da pesquisa a qualquer tipo de desconforto e risco para sua saúde.

A utilização de uma metodologia adequada é uma questão fundamental na definição da validade científica da pesquisa. Entendida como uma disciplina, a pesquisa (ou a investigação) tem sempre como objetivo a busca de um novo conhecimento sendo, portanto, um processo de renovação da própria pesquisa e a metodologia tem esse efeito disciplinador.

A questão é: a ética médica e a bioética devem ser entendidas como disciplinas e com isto, com um tratamento metodológico específico.

Com relação aos problemas do exercício da medicina (ética médica), pode-se entender que os questionamentos em determinadas situações se assemelham ao que ocorre na pesquisa, quando a investigação, com metodologia adequada, pode contribuir para melhor entendimento da questão. Quando há uma denúncia, aos conselhos de ética médica, sobre o alegado erro médico relacionado a uma determinada situação de pratica médica, o julgador, inicialmente, deve considerar os aspectos técnicos relacionados ao diagnóstico, ao procedimento realizado, as intercorrências e etc, que poderiam caracterizar uma possível infração ao Código de Ética Médica. Nesta avaliação, sem dúvida, deve ser levado em consideração os aspectos técnico-científico do procedimento realizado pelo médico e que estão sendo questionados do ponto de vista ético. Diante da evidência de que o procedimento não foi corretamente executado pelo médico há o julgamento ético. Em resumo, diante de uma possível infração ao Código de Ética Médica o julgador usa de uma metodologia técnico-científica, como ponto de partida, para o julgamento ético do médico envolvido na denúncia de infração.

Eis que surge a diferença entre a ética médica e a bioética: a ética médica, por natureza, tem caráter disciplinador da atividade do médico na sua prática 
cotidiana. O mesmo ocorre quando o médico desenvolve uma pesquisa com seres humanos havendo a obrigatoriedade de se aos dispositivos que regulamentam a pesquisa (Resolução 196/96 do CNS) ${ }^{6}$.

Voltamos a insistir: a atividade prática do médico está disciplinada no Código de Ética Médica e a atividade de pesquisa, nas resoluções sobre pesquisa com seres humanos; enquanto, a bioética é o campo de reflexão sobre os valores envolvidos nas ciências da vida.

Nesse ponto, é importante entender o conceito, desse novo campo do saber, que é a bioética: "estudo sistemático das dimensões morais - incluindo a visão moral, decisões, condutas e políticas - das ciências da vida e dos cuidados da saúde, empregando uma variedade de metodologias éticas em um ambiente interdisciplinar."

No Brasil, a bioética tem como temas: desigualdades sociais, equidade, questões demográficas e populacionais; responsabilidade individual e coletiva sobre assistência à saúde; alocação de recursos, pobreza, racismo; saúde pública e políticas sanitárias e justiça sanitária; reprodução assistida, medicina fetal, eutanásia e outros.

É interessante observar que os temas levantados pela bioética são, na prática, os mesmos que tem sido levantados pelos médicos e suas entidades junto à sociedade procurando definir caminhos normativos que orientem os profissionais. Não obstante, a bioética pode estabelecer uma ponte com a ética médica abrindo um espaço de reflexão com estímulos para a produção de saberes não necessariamente normativos.

Oliveira RA de. Bioethics and medical ethics. Saúde, Ética \& Justiça. 2005;10(1/2):26-8.

ABSTRACT: The expression medical ethics may be defined as what physicians usually say "to follow what is determined by the ethics code": duties and rights of physicians". Bioethics is an area of human knowledge which relates ethic values with biological facts mainly those facts which involve life and health of human beings within a proper environment.

KEY WORDS: Medical, ethics. Bioethics.

\section{REFERÊNCIAS}

1. Jonsen AR. A breve história da ética médica/A short history of medical ethics. New York: Oxford University; 2000.

2. Oselka GW. O código de ética médica. In: Segre M, Cohen C, organizadores. 3a ed. rev ampl. São Paulo: Editora da Universidade de São Paulo; 2002.

3. Conselho Federal de Medicina. Código de ética médica: resolução CFM 1.246/88.
4. Matte US. Aspectos éticos, legais e sociais. In: Mir L, organizador. Genômica. São Paulo: Atheneu; 2004.

5. Garrafa V. Ética aplicada, exclusão social e educação no contexto dos países do hemisfério sul. In: Segre $M$, organizador. A questão ética e a saúde humana. São Paulo: Atenheu; 2006.

6. Cadernos de Ética em Pesquisa. Comissão de Ética em Pesquisa. 1998 jun;1(1). 